\section{Polar Research's referees}

It is once again time to thank all the scientistsnot only those whose names are printed on the following pages - who have kindly served as referees for Polar Research during the last couple of years.

There is a widespread sentiment that reviewing manuscripts is an almost thankless task. Yet reviewers agree to it anyway. Why? This was one of the questions addressed in a focus group study commissioned by the publishers Elsevier (Mulligan 2004). The study confirmed that reviewers are motivated by a number of factors. Chief among them is the perception that it is one's academic duty to review others' papers since one's own work is similarly reviewed (and, thereby, often improved). Additional incentives for referees include a wish to remain up-to-date in their fields and the hope that reading new work will stimulate fresh ideas for their own research. The study indicates that the reputation of the journal strongly influences a reviewer's decision to agree to examine a manuscript, and it helps if the referee personally knows the individual requesting the review.

The Elsevier study also revealed that referees believe that reviewing is growing more burdensome. Referees are being swamped with requests to review manuscripts and the turnaround times demanded by editors - themselves pressured by authors who want fast decisions and rapid publication - are becoming shorter. Some fields are more impacted by this than others. Scientists in "high consensus" fields - in which scholars agree about what constitutes good research and fruitful theory-are likelier to compete for priority in announcing their findings and to worry about being scooped by rivals (Hargens 1990). Competition for priority is more pronounced in the physical sciences than in the biological sciences (Hargens 1990 and sources cited therein), yet expectations for speedier turnaround and publication pervade scientific publishing. These expectations have surely been influenced by the possibilities of computer technology, which allows for lightning-fast communication and quicker preparation of documents and graphics. (As with so many other aspects of modern life, the better the technology, the more we humans must scramble to keep pace.) The internet revolution seems to have aggravated the situation for reviewers in one further respect. Referees in the Elsevier focus group felt that online review, which is in use at many journals (but not yet Polar Research), benefits authors and editors but places an extra load on the shoulders of reviewers. They have to print out manuscripts themselves and must confine their comments to restrictive online formats. (See Gladwell [2002] for a look at how and why many people-_knowledge workers", in particularcontinue to rely on paper in spite of the prediction that it would be made largely obsolete by today's information technology.) Editors who participated in the Elsevier study felt that attracting and keeping good referees is getting harder.

Rushed, overburdened and sometimes feeling unappreciated, referees can at least take heart in the fact that editors are deeply concerned with their plight as well as with the larger issues relating to peer review. In September 2005, for example, 470 participants representing 38 nations gathered in Chicago for three days for the Fifth International Congress on Peer Review and Biomedical Publishing. Presentations at the conference covered topics such as conflicts of interest, blind peer review and comparisons of the quality of reviews by editor- as opposed to author-suggested referees. Though a majority of the talks and posters were specific to biomedical publishing, many contained messages of broader relevance. (For the complete program see www.amaassn.org/public/peer/program.html.) Peer review is a common topic of discussion in European Science Editing, the (peer reviewed) journal of the European Association of Science Editors.

What is the purpose of peer review? As Mulligan (2004) points out, there is no single set of objectives which is universally in use. The consensus in the focus group in the Elsevier study was that "peer review should prevent an author making egregious claims on minimal results... it should ensure that a consistent and appropriate methodology is used, and that recent reputable work...is correctly referenced and acknowledged" (Mulligan 2004: 4). These basic criteria form the backbone of Polar Research's reviewer's guidelines and, presumably, those of other scientific journals. On these grounds, referees evaluate manuscripts; those failing to satisfy the most important criteria are rejected by editors. According to Meadows (2005: 114), the rejection rate of the "average" natural science journal does not exceed a third of submissions. Interestingly, in 

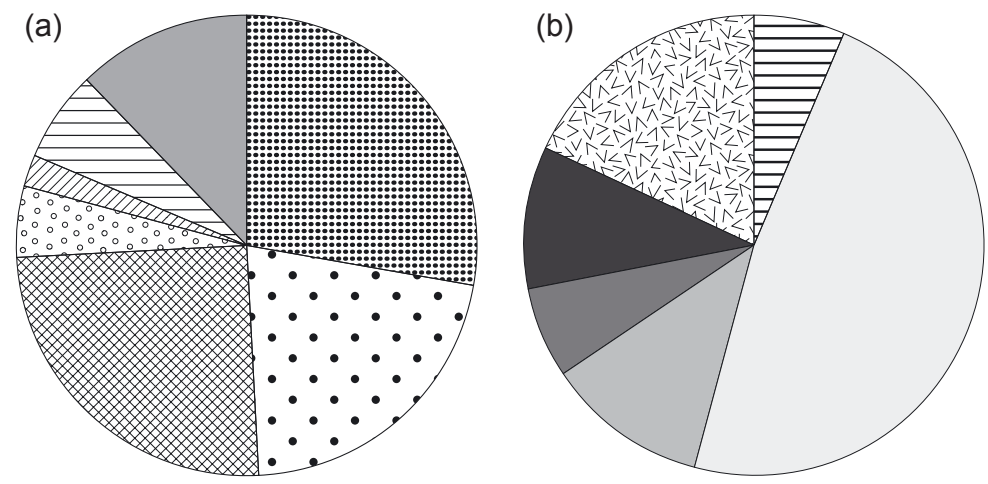

Fig. 1. (a) A rough breakdown of the scientific fields represented in Polar Research articles; (b) the geographic areas that the journal's articles concern. The data are drawn from the last five years.

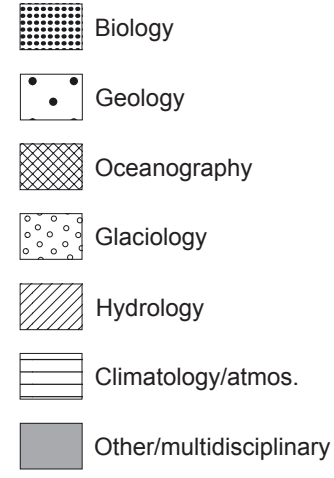

the social sciences-where there is low consensus about what constitutes valuable researchjournals reject two-thirds or more of their submissions, and they require more revisions from authors (Meadows 2005; see also Hargens 1990).

In contrast to many journals, Polar Research is multidisciplinary; its scope is largely defined by geography and it therefore competes for submissions with journals covering particular scientific fields. Biology, geology and oceanography are all well representd in Polar Research: combined, these three disciplines represent about three-quarters of the articles in the journal (Fig. 1a). In terms of geographical coverage, the Nordic Arctic, particularly Svalbard and the Barents Sea, continues to dominate the pages of Polar Research (Fig. 1b). Only about $6 \%$ of the journal's articles concern the Antarctic. This is an imbalance that the journal's contributors, referees and readers can help to rectify by spreading the word that the scope of Polar Research encompasses both poles.

Helle V. Goldman

Norwegian Polar Institute, Polar Environmental Centre,NO-9296Tromsø,Norway,goldman@npolar.no.
Antarctica

Continental Nordic Arctic/

Nordic seas/Svalbard

Russian Arctic/seas

North American Arctic

Greenland/Iceland

Other/multiple

\section{References}

Gladwell, M. 2002: The social life of paper: looking for method in the mess. The New Yorker 25 March, 92-96.

Hargens, L. L. 1990: Variation in journal peer review systems: possible causes and consequences. J. Am. Med. Assoc. 263, 1348-1352.

Meadows, J. 2005: Differences between the sciences in their handling of the research literature. Eur. Sci. Ed. 31, 113116.

Mulligan, A. 2004: Is peer review in crisis? Perspect. Publ. $2,1-6$. 
Becky Alexander, University of Washington, USA

Ole B. Andersen, Danish National Space Center, Denmark

Peter G. Appleby, University of Liverpool, UK

Steven A. Arcone, Cold Regions Research and

Engineering Laboratory, USA

Holger Auel, University of Bremen, Germany

Wilfried Bauer, RWTH Aachen University, Germany

Martin Beniston, University of Fribourg, Switzerland

Matthew Bennett, Bournemouth University, UK

Knut Bjørlykke, University of Oslo, Norway

Johan Blindheim, Institute of Marine Research, Norway

Dierk P. G. Blomeier, Norwegian Polar Institute, Norway

Corey J. A. Bradshaw, Charles Darwin University, Australia

Keith Brander, International Council for the Exploration of the Sea, Denmark

Howard I. Browman, Institute of Marine Research, Norway

Iain B Campbell, Land and Soil Consultancy Services, New Zealand

Alex J. Cannon, Meteorological Service of Canada, Canada

Hanne H. Christiansen, The University Centre in Svalbard, Norway

Andrew Davidson, Australian Antarctic Division, Australia

Daniel Delille, National Center of Scientific Research, France

Julian Dowdeswell, Scott Polar Research Institute, UK

Dennis G. Dye, Frontier Research Center for Global Change, Japan

Henning Dypvik, University of Oslo, Norway Bernd Etzelmüller, University of Oslo, Norway Julian B. Fischer, US Fish and Wildlife Service, USA

I. V. Florinsky, Institute of Mathematical Problems of Biology, Russia

Giles M. Foody, University of Southampton, UK Steven L. Forman, University of Illinois, USA

Jean-Marc Fromentin, French Research Institute for Exploitation of the Sea, France

Robert Gilbert, Queen's University, Canada

Philip A. Gillibrand, Scottish Association for Marine Science, UK

John Gjelberg, Hydro Research Centre, Norway William Gould, International Institute of
Tropical Forestry, Puerto Rico

Viktor Gouretski, Max Planck Institute for Meteorology, Germany

T. G. Allan Green, Waikato University, New Zealand

Sveinn Are Hanssen, University of Tromsø, Norway

E. Walter Helbling, Photobiological Station at Playa Union, Argentina

Gerhard J. Herndl, Royal Netherlands Institute for Sea Research, The Netherlands

J. Mark Hipfner, Canadian Wildlife Service, Canada

G. J. Greg Hofmeyr, University of Pretoria, South Africa

Ólafur Ingólfsson, University of Iceland, Iceland

Elisabeth Isaksson, Norwegian Polar Institute, Norway

George D. Jackson, University of Tasmania, Australia

L. Allan James, University of South Carolina, USA

Hester Jiskoot, University of Lethbridge, Canada Ludger Kappen, University of Kiel, Germany Michael Karcher, Alfred Wegener Institute for Polar and Marine Research, Germany

Ron Kwok, Jet Propulsion Laboratory, USA

Mary-Anne Lea, University of Tasmania, Australia

Victoria Lytle, WCRP Climate and Cryosphere International Project Office, Norway

Harald Loeng, Institute of Marine Reseach, Norway

J. I. López-Moreno, Pyrenean Institute of Ecology CSIC, Spain

Connie Lovejoy, Laval University, Canada

Rosa Margesin, Leopold Franzens University, Austria

Thomas Martin, University of Kiel, Germany

Robert V. Miller, Oklahoma State University, USA

Anders Mosbech, National Environmental Research Institute, Denmark

Ellen Mosley-Thompson, The Ohio State University, USA

Ransom A. Myers, Dalhousie University, Canada

Adrian Neal, University of Wolverhampton, UK Patrick J. Neale, Smithsonian Institution, USA

Marco Nigro, University of Pisa, Italy

Carsten Riis Olesen, National Environmental Research Institute, Denmark

Brad Page, South Australian Research and 
Development Institute, Australia

Ana Pintado, Complutense University of Madrid, Spain

Francesco Regoli, Polytechnic University of Marches-Ancona, Italy

Gregory J. Robertson, Canadian Wildlife Service, Canada

Martin J. Siegert, University of Bristol, UK

Elizabeth Sinclair, National Oceanic and Atmospheric Administration, USA

Walter H. F. Smith, National Oceanic and Atmospheric Administration, USA

Hans-Ulrich Steeger, University of Muenster, Germany

Ron Steel, The University of Texas at Austin, USA

Daniel Steinhage, Alfred Wegener Institute, Germany

Douglas Stow, San Diego State University, USA

Nicholas Tyler, University of Tromsø, Norway

Roberto Udisti, University of Florence, Italy

Arnoldo Valle-Levinson, University of Florida,
USA

John van den Hoff, Australian Antarctic Division, Australia

Alan P. M. Vaughan, British Antarctic Survey, UK

Virginia E. Villafañe, Photobiological Station at Playa Union, Argentina

Peter Wadhams, University of Cambridge, UK

David Walsh, Naval Research Laboratory, USA

Jenny G. Webster-Brown, University of Auckland, New Zealand

Meredith Williams, University of Newcastle upon Tyne, UK

Peter Winsor, Woods Hole Oceanographic Institution, USA

David Worsley, Rogaland Research Institute, Norway

Daqing Yang, University of Alaska Fairbanks, USA

Kathy L. Young, York University, Canada

Richard E. Young, University of Hawaii, USA

Howard Zebker, Stanford University, USA 